\title{
Clinical efficacy of modified phacoemulsification in the treatment of high myopia with cataract: a systematic review and meta-analysis
}

\author{
Jia Qi ${ }^{1 \#}$, Jun Yuan ${ }^{1 \#}$, Yun Zhou ${ }^{1}$, Rui Guo ${ }^{1}$, Yue Zhang ${ }^{1}$, Qing Dai ${ }^{1}$, Yongli Liu ${ }^{2}$ \\ ${ }^{1}$ Department of Ophthalmology, Taihe Hospital, Hubei University of Medicine, Shiyan, China; ${ }^{2}$ Department of Nursing, Taihe Hospital, Hubei \\ University of Medicine, Shiyan, China \\ Contributions: (I) Conception and design: J Qi, J Yuan, Y Liu; (II) Administrative support: Y Liu; (III) Provision of study materials or patients: J \\ Qi, Y Zhou, R Guo; (IV) Collection and assembly of data: J Yuan, Y Zhang, Q Dai; (V) Data analysis and interpretation: J Qi, J Yuan, Y Liu; (VI) \\ Manuscript writing: All authors; (VII) Final approval of manuscript: All authors. \\ "These authors contributed equally to this work as co-first authors. \\ Correspondence to: Yongli Liu. Department of Nursing, Taihe Hospital, Hubei University of Medicine, Renmin Middle Road, Shiyan 442000, China. \\ Email: 778006045@qq.com.
}

\begin{abstract}
Background: To use meta-analysis to evaluate the clinical effect of modified phacoemulsification in the treatment of high myopia with cataract.

Methods: The English language databases of PubMed, Web of Science, and Embase, and Chinese language databases China National Knowledge Infrastructure (CNKI) and Wanfang were searched for relevant studies published from January 2010 to May 2021. The participants were divided into 2 groups according to different treatment methods; the control group mainly used traditional phacoemulsification, while the treatment group used modified phacoemulsification. The differences in the postoperative complication rate, visual acuity recovery rate at 1 month after surgery, and corneal endothelial cell count at 1 and 3 months after surgery were analyzed.

Results: A total of 12 articles were included. The results of comparison confirmed that the treatment group was superior to the control group in the postoperative complication rate, visual acuity recovery rate at 1 month after surgery, and corneal endothelial cell count at 1 and 3 months after surgery.

Discussion: Both treatment methods are effective, but modified phacoemulsification has greater advantages in reducing the damage of corneal endothelial cells and postoperative complications and in improving patient prognosis. Additionally, modified phacoemulsification in the treatment of high myopia with cataract can achieve better visual acuity recovery than traditional phacoemulsification, suggesting a high value for clinical application.
\end{abstract}

Keywords: High myopia; cataract; modified phacoemulsification; clinical efficacy; meta-analysis

Submitted Jul 30, 2021. Accepted for publication Sep 03, 2021.

doi: 10.21037/apm-21-2215

View this article at: https://dx.doi.org/10.21037/apm-21-2215

\section{Introduction}

Myopia is common in daily life, can be corrected with glasses, contact lenses, and refractive surgery, and is therefore considered a benign disease (1). However, if myopia cannot be completely corrected, it is the leading hidden cause of visual impairment. In Europe and East Asia, high myopia is the main cause of blindness (2). High myopia is characterized by axial length elongation and stretching of the posterior eye wall. It also causes a variety of specific complications, including cataract, chorioretinal atrophy, and macular hole with or without retinal detachment, myopic foveoschisis, or optic nerve head changes. The 
majority of these complications are damaging to vision, usually resulting in irreversible retinal photoreceptor impairment and consequently central vision loss (3). In some people with high myopia, myopia-associated cataract is the most common cause of irreversible blindness. Pan et al. demonstrated an association between myopia and nuclear and posterior subcapsular cataracts (4). Additionally, a direct link between high myopia and cataract has been found, especially with nuclear (a 3-to-5-fold increase in risk) and posterior capsular cataract (a 30\% increase in risk) (5). Current clinical treatment for high myopia with cataract includes drug therapy, surgery, and alternative therapies. However, current clinical reports have shown that their efficacy is unsatisfactory (6). There is therefore an urgent need to find or establish a new treatment.

Compared with conventional extracapsular cataract extraction (ECCE) or intracapsular cataract extraction (ICCE), phacoemulsification is effective and less risky in the treatment of high myopia with cataract. However, it has been reported that within 10 years after phacoemulsification, the incidence of pseudophakic retinal detachment (PPRD) is between $0.36-2.9 \%$, and although the number decreases by $0.1-0.2 \%$ per year, it remains a source of concern (7). The risk of PPRD is about 10 times that of rhegmatogenous retinal detachment (RRD) in the general population due to factors including intraoperative vitreous loss, increasing axial length, and increasing age (8). Modified phacoemulsification has been introduced with the aim of improving the efficacy of phacoemulsification and avoiding its adverse effects. In relevant clinical reports, modified phacoemulsification has shown safety and efficacy in the treatment of high myopia with cataract $(9,10)$; but there is no consensus on this topic, and many studies have not yet comprehensively evaluated its effectiveness and safety. Therefore, by collecting recently published studies, we systematically reviewed and analyzed the clinical efficacy of modified phacoemulsification in the treatment of high myopia with cataract, thus providing a reference for the clinical treatment and prognosis evaluation of this condition. We present the following article in accordance with the PRISMA reporting checklist (available at https://dx.doi.org/10.21037/apm-21-2215).

\section{Methods}

\section{Literature search method}

The databases of PubMed, Web of Science, Embase, China National Knowledge Infrastructure (CNKI), and Wanfang were searched for relevant English and Chinese studies published from January 2010 to May 2021. The search terms used were as follows: "Modified phacoemulsification" and "High myopia" and "Cataract".

\section{Inclusion criteria}

(I) Participants: patients who met the diagnostic criteria for high myopia with cataract. (II) Grouping: in the control group, traditional phacoemulsification was mainly used. Specifically, the lens nucleus was fragmented using the chopping method, followed by the suction of the fragments; the lamellar scleral incision was expanded to $5.5 \mathrm{~mm}$, followed by rigid intraocular lens implantation. In the treatment group, modified phacoemulsification was mainly used. Specifically, with a $3.00 \mathrm{~mm}$ corneal incision in the upper left corner of the affected side and an auxiliary incision in the upper right corner of the limbus, a circular capsulorhexis was performed; the energy, flow rate, and maximum negative pressure of the ultrasonic phacoemulsifier were adjusted for nucleus chopping; the incision was then expanded according to the different characteristics of the residual hard nucleus to remove it; the cortex was aspirated, and an intraocular lens was implanted. (III) Outcome measures: at least including any of the postoperative complication rate, visual acuity recovery rate 1 month after surgery, and preoperative corneal endothelial cell count before surgery, 1 month after surgery, and 3 months after surgery. (IV) Design: randomized controlled trials.

\section{Exclusion criteria}

(I) Studies in which the data required for this meta-analysis were not provided, unable to be obtained, and the original text was unavailable; (II) literatures with poor quality, missing data, and duplicate literatures; (III) non-cataract related literatures, case reports, systematic reviews, and animal experiments.

\section{Data extraction}

Literature screening was completed by 2 investigators independently according to screening criteria. Specifically, the investigators excluded studies by reading titles, abstracts, and even full text, and the corresponding materials were cross-checked to finally determine the literature included in this study.

The following data were extracted from the studies: first 


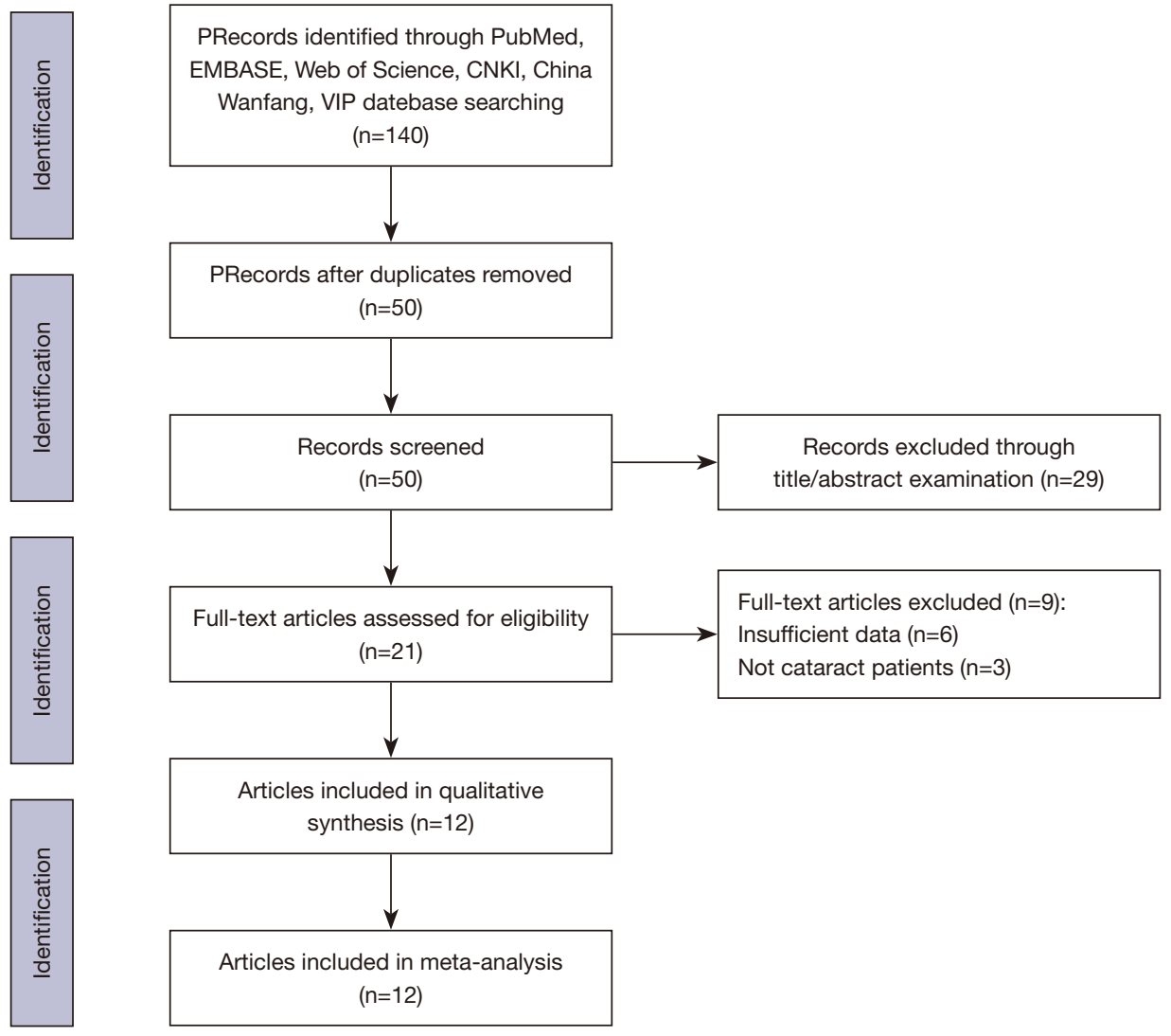

Figure 1 Literature screening process.

author, year of publication, study location, study design, main outcome measures, number of cases and controls, study duration, adjusted confounders, and multivariable adjusted odds ratio (OR) with $95 \%$ confidence intervals (CI). During data extraction, disagreements between the 2 investigators were resolved by referring to the original literature and subsequent discussion with each other.

\section{Statistical analysis}

The software Review Manager 5.3 (RevMan, Copenhagen: The Nordic Cochrane Center, The Cochrane Collaboration, 2014) was utilized for statistical analysis, and dichotomous variables were compared using weighted mean difference (WMD) and OR, respectively. Assessment of heterogeneity was completed using $\mathrm{Q}$ test and $\mathrm{I}^{2}$ statistic. In the case of significant heterogeneity $\left(\mathrm{I}^{2}>50 \%\right)$, the random effects model was adopted; otherwise, the fixed effects model was employed. Sensitivity analysis and publication bias assessment were also performed in this study using
Stata 16.0 (StataCorp., College station, TX, USA).

\section{Results}

\section{Literature screening results}

Initially, a total of 140 relevant articles were obtained according to the search terms, and then 90 duplicate articles were excluded. A further 29 articles were excluded on account of irrelevance after reading their titles/abstracts. There were 6 articles with missing data, and 3 studies unrelated to high myopia with high myopia that were also excluded. Finally, 12 articles that met the inclusion criteria were included in this meta-analysis (11-22). The screening process and results are presented in Figure 1, and their basic characteristics are shown in Table 1.

\section{Postoperative complications and visual acuity recovery 1 month after surgery}

A total of 10 articles reported the postoperative complication 
Table 1 Basic characteristics of the included articles

\begin{tabular}{|c|c|c|c|c|c|c|c|c|c|c|c|}
\hline Study & Year & Sample time & $\begin{array}{c}\text { Patient } \\
\text { cases } \\
\text { Treat/Con }\end{array}$ & $\begin{array}{c}\text { Eyes } \\
\text { Treat/Con }\end{array}$ & \multicolumn{2}{|c|}{ Age (years) } & \multicolumn{2}{|c|}{ Gender (M/FM) } & $\begin{array}{l}\text { Nuclear } \\
\text { opacity }\end{array}$ & $\begin{array}{l}\text { Study } \\
\text { design }\end{array}$ & $\begin{array}{l}\text { Outcome } \\
\text { measures }\end{array}$ \\
\hline Ronghua Chen & 2014 & 2012.11-2013.11 & $50 / 50$ & $67 / 54$ & $63.4 \pm 3.8$ & $63.4 \pm 3.8$ & NP & NP & III-V & $\mathrm{RCT}$ & $\mathrm{a}, \mathrm{b}, \mathrm{c}, \mathrm{d}, \mathrm{e}$ \\
\hline Bingbing Feng & 2014 & 2011.08-2013.12 & $65 / 73$ & $75 / 75$ & $61.9 \pm 11.2$ & $62.1 \pm 10.9$ & $35 / 30$ & $40 / 33$ & III-V & $\mathrm{RCT}$ & $\mathrm{a}, \mathrm{b}, \mathrm{c}, \mathrm{d}, \mathrm{e}$ \\
\hline Chao Yang & 2018 & 2016.03-2017.12 & $52 / 52$ & $75 / 69$ & $60.5 \pm 5.3$ & $59.7 \pm 5.6$ & $30 / 22$ & $29 / 23$ & NP & $\mathrm{RCT}$ & $a, b, d, e$ \\
\hline Dongmei Li & 2017 & 2013.05-2016.05 & $28 / 28$ & $48 / 38$ & $60.4 \pm 8.8$ & $61.5 \pm 7.8$ & $15 / 13$ & $14 / 14$ & III-V & $\mathrm{RCT}$ & $a, b, d, e$ \\
\hline Mingbing Zeng & 2020 & 2012.01-2016.12 & $130 / 134$ & $130 / 134$ & $68.7 \pm 10.5$ & $68.9 \pm 10.1$ & $63 / 67$ & $65 / 69$ & IV-V & $\mathrm{RCT}$ & $a, d$ \\
\hline Kongsap Pipat & 2019 & $2016.05-2017.03$ & $21 / 21$ & $21 / 21$ & $62.3 \pm 4.0$ & $68.6 \pm 1.9$ & $7 / 14$ & $8 / 13$ & $\mathrm{II}-\mathrm{V}$ & $\mathrm{RCT}$ & $b, c, d, e$ \\
\hline Xiaorong Zhang & 2019 & 2017.01-2018.01 & $50 / 50$ & $50 / 50$ & $60.3 \pm 5.2$ & $60.9 \pm 5.6$ & $28 / 22$ & $25 / 25$ & NP & $\mathrm{RCT}$ & $a, b, d, e$ \\
\hline Chunwei Zhou & 2021 & 2016.03-2018.05 & $15 / 15$ & $30 / 30$ & $59.2 \pm 3.3$ & $58.1 \pm 3.5$ & $8 / 7$ & $9 / 6$ & NP & $\mathrm{RCT}$ & $c, d, e$ \\
\hline
\end{tabular}

a, postoperative complications rate; b, visual acuity recovery rate 1 month after surgery; c, preoperative corneal endothelial cell count; $d$, corneal endothelial cell count at 1 month postoperatively; e, corneal endothelial cell count at 3 months postoperatively. Treat, treatment group; Con, control group; M, male; FM, female; NP, not reported; RCT, randomized controlled trial.

rate in the 2 groups. No significant heterogeneity was identified among the studies $\left(\mathrm{I}^{2}=0.00 \%, \mathrm{P}=0.824\right)$, so the fixed effects model was used for analysis. The result showed a lower postoperative complication rate in the treatment group compared with the control group ( $\mathrm{OR}=0.13,95 \% \mathrm{CI}$ : 0.09 to 0.19$)$ (Figure $2 A$ ).

A total of 10 articles compared the visual acuity recovery 1 month after surgery between the 2 groups. No significant heterogeneity was identified among the studies $\left(\mathrm{I}^{2}=0.00 \%\right.$, $\mathrm{P}=0.991$ ), so the fixed effects model was used for analysis. The results revealed that the visual acuity recovery 1 month after surgery in the treatment group was superior to that in the control group (OR $=0.45,95 \% \mathrm{CI}: 0.25$ to 0.80) (Figure 2B).

Further, the funnel plots were mostly symmetrical, suggesting a small possibility of publication bias in the included articles (Figure $3 A, 3 B$ ). Then, in order to determine the sensitivity of meta-analysis results, sensitivity analysis was performed by removing included articles one by one. The results showed that the pooled effect size was still of statistical significance, and there were no significant changes in the direction of forest plots before and after removal (Figure $4 A, 4 B$ ).

\section{Corneal endothelial cell count at different stages in the 2 groups}

A total of 6 articles compared preoperative corneal endothelial cell count. No significant heterogeneity was identified among the studies $\left(\mathrm{I}^{2}=0.00 \%, \mathrm{P}=0.987\right)$, so the fixed effects model was used for analysis. The result showed no significant difference in the preoperative corneal endothelial cell count between the two groups $(\mathrm{OR}=0.01$, 95\% CI: -0.14 to 0.16 ) (Figure $5 A$ ), suggesting that this index was comparable.

A total of 12 articles compared corneal endothelial cell counts 1 month after surgery. No significant heterogeneity was identified among the studies $\left(\mathrm{I}^{2}=7.30 \%, \mathrm{P}=0.373\right)$, so the fixed effects model was used for meta-analysis. The result showed that at 1 month after surgery, the number of corneal endothelial cells in the treatment group was significantly higher than that in the control group (OR $=0.68,95 \%$ CI: 0.58 to 0.78 ) (Figure $5 B$ ).

A total of 10 articles compared corneal endothelial cell counts 3 months after surgery. No significant heterogeneity was identified among the studies $\left(\mathrm{I}^{2}=34.8 \%, \mathrm{P}=0.129\right)$, so the fixed effects model was used for meta-analysis. The 
A Study

$\mathrm{OR}(95 \% \mathrm{Cl}) \quad$ Weight

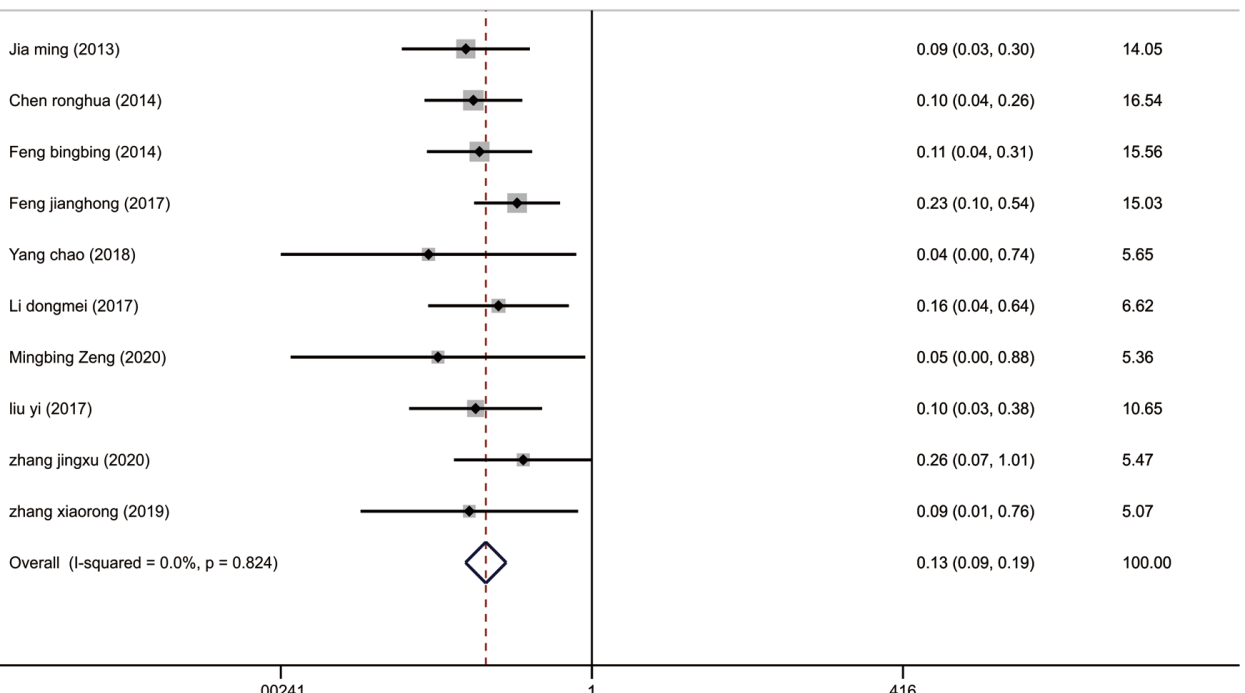

B Study

OR $(95 \% \mathrm{Cl}) \quad$ Weight

\begin{tabular}{|c|c|c|c|}
\hline Jia ming (2013) & 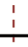 & $0.32(0.03,3.12)$ & 8.21 \\
\hline Chen ronghua (2014) & & $0.38(0.07,2.18)$ & 11.76 \\
\hline Feng bingbing (2014) & & $0.49(0.04,5.56)$ & 5.40 \\
\hline Feng jianghong (2017) & & $0.66(0.18,2.38)$ & 15.88 \\
\hline Yang chao (2018) & & $0.22(0.02,2.01)$ & 11.25 \\
\hline Li dongmei (2017) & & $0.38(0.03,4.39)$ & 5.98 \\
\hline Kongsap Pipat (2019) & & $0.47(0.04,5.68)$ & 5.21 \\
\hline liu yi (2017) & & $0.51(0.04,5.79)$ & 5.27 \\
\hline zhang jingxu (2020) & & $0.69(0.21,2.30)$ & 17.61 \\
\hline zhang xiaorong (2019) & & $0.18(0.02,1.63)$ & 13.41 \\
\hline Overall (I-squared $=0.0 \%, p=0.991$ ) & & $0.45(0.25,0.80)$ & 100.00 \\
\hline
\end{tabular}

Figure 2 Forest plots between the 2 groups. (A) Postoperative complications. (B) Visual acuity recovery 1 month after surgery. 

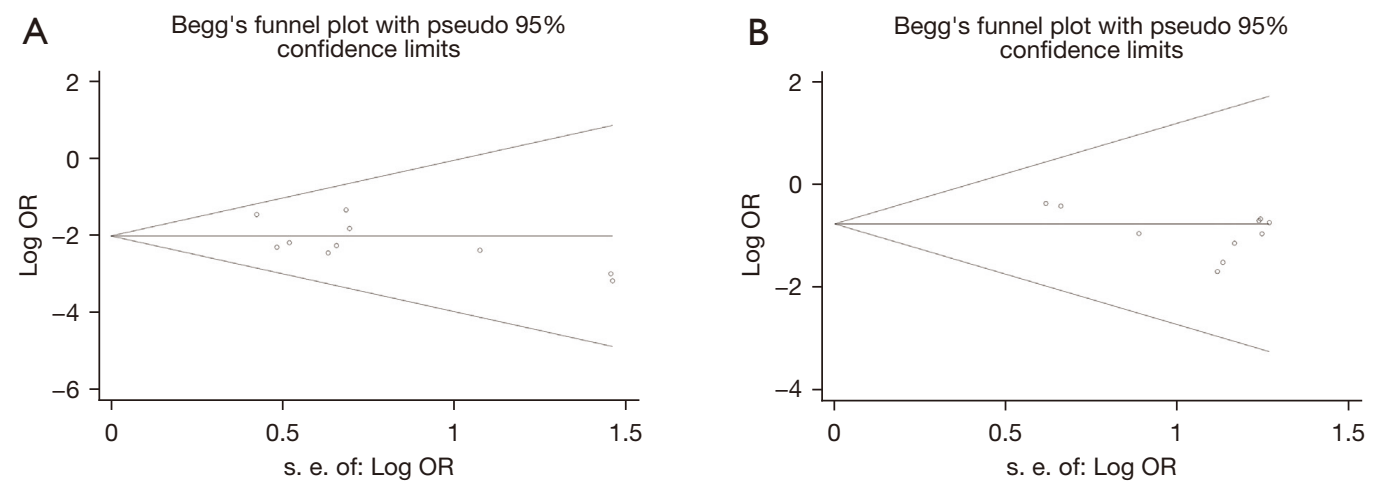

Figure 3 Funnel plots between the 2 groups. (A) Postoperative complications. (B) Visual acuity recovery 1 month after surgery.
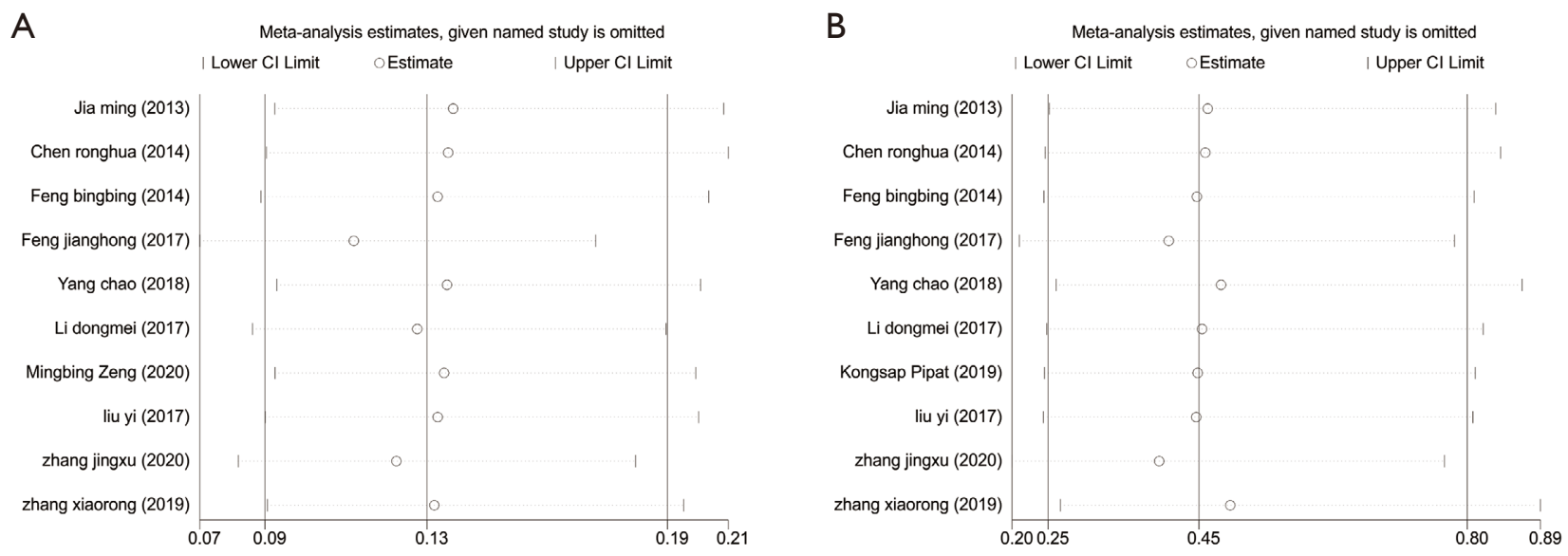

Figure 4 Sensitivity analysis between the 2 groups. (A) Postoperative complications. (B) Visual acuity recovery 1 month after surgery.

result showed that at 3 months after surgery, the number of corneal endothelial cells in the treatment group was significantly higher than that in the control group (OR $=0.65$, 95\% CI: 0.53 to 0.77 ) (Figure 5C).

Further, the funnel plots were mostly symmetrical, suggesting a small possibility of publication bias in the included articles (Figure 6A,6B). Then, in order to determine the sensitivity of meta-analysis results, sensitivity analysis was performed by removing included articles one by one. The results showed that the pooled effect size was still of statistical significance, and there were no significant changes in the direction of forest plots before and after removal (Figure $7 A-7 C$ ).

\section{Discussion}

Retinal detachment after cataract surgery is a prevalent complication, with $0.93 \%$ incidence in the general population and $2.2 \%$ in high myopia patients (23). Thus, it can be seen that cataract surgery in patients with high myopia is complicated. Some studies have reported that the prevalence of myopia in contemporary young people is as high as $83 \%$, which is higher than that of the elderly by about $30 \%$. This result indicates that in the near future, due to intergenerational effects, the prevalence of myopia will increase significantly in people over 45 years old and consequently increase the number of high myopia patients, as well as high myopia with cataract (24). In clinical practice, phacoemulsification with an intraocular lens has achieved many results, but more problems have been exposed with the increasing number of applications. Specifically, traditional phacoemulsification for cataract patients clinically increases the risk of PPRD in the early postoperative period, and reduces the time of PPRD from 31 to 10 months in patients 


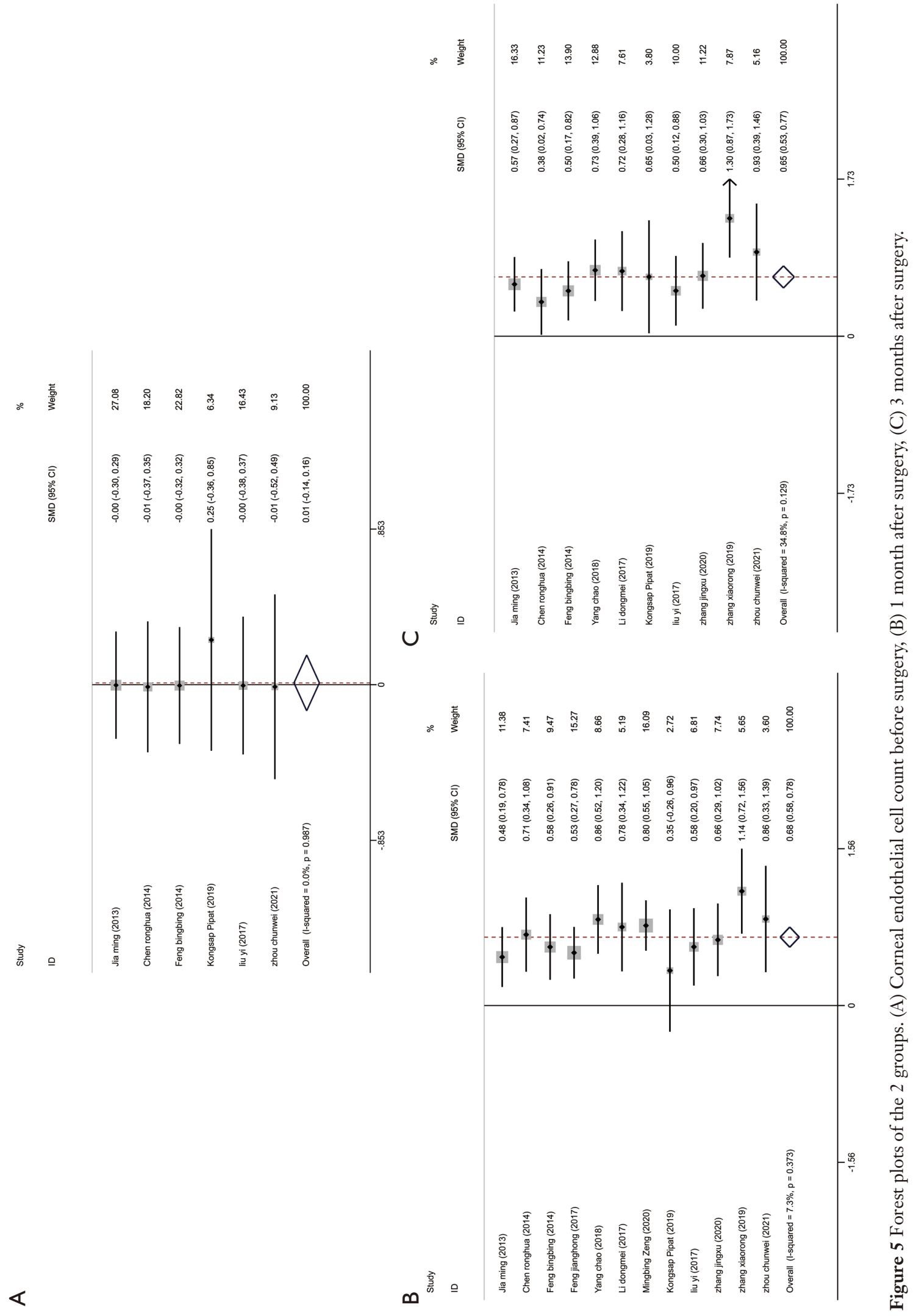



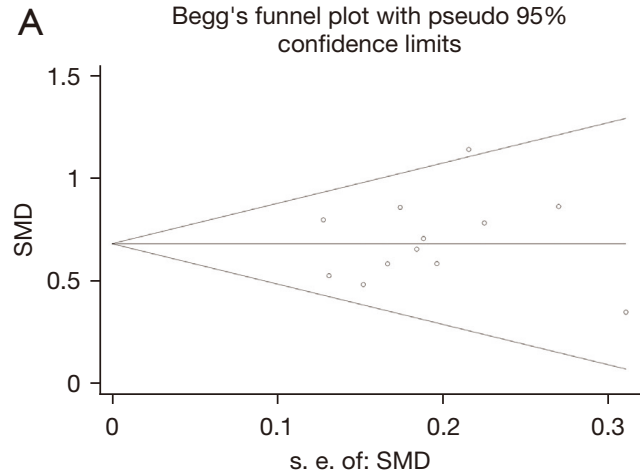

B Begg's funnel plot with pseudo $95 \%$

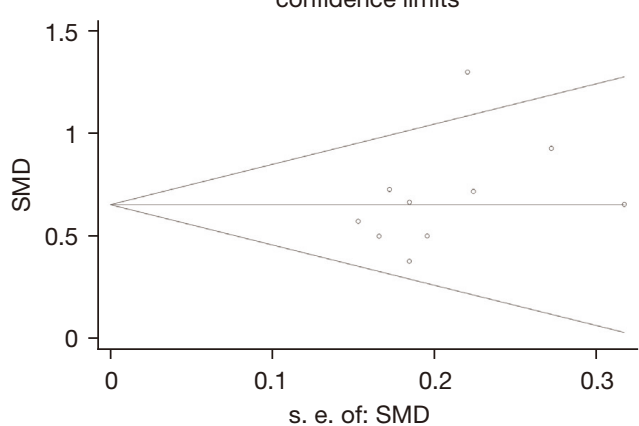

Figure 6 Funnel plots of corneal endothelial cell count in the 2 groups. (A) 1 month after surgery, (B) 3 months after surgery.

A

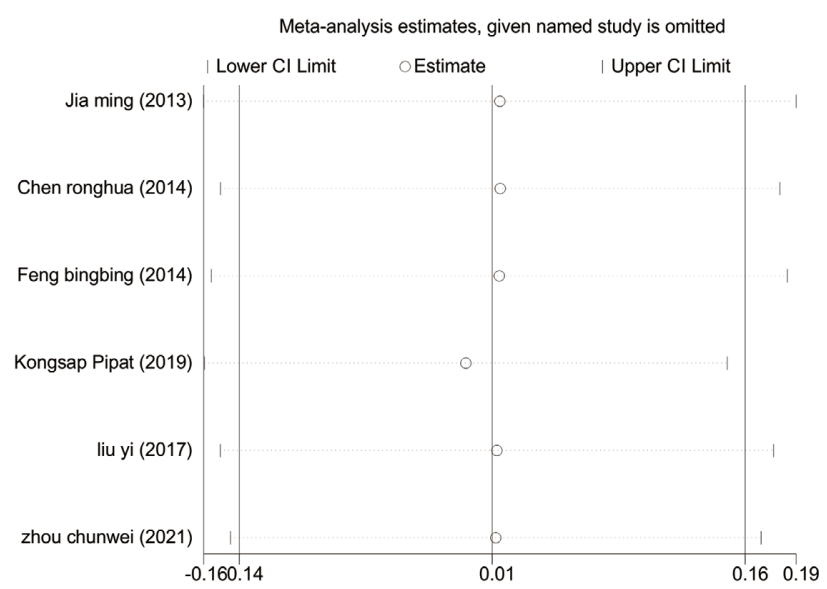

B

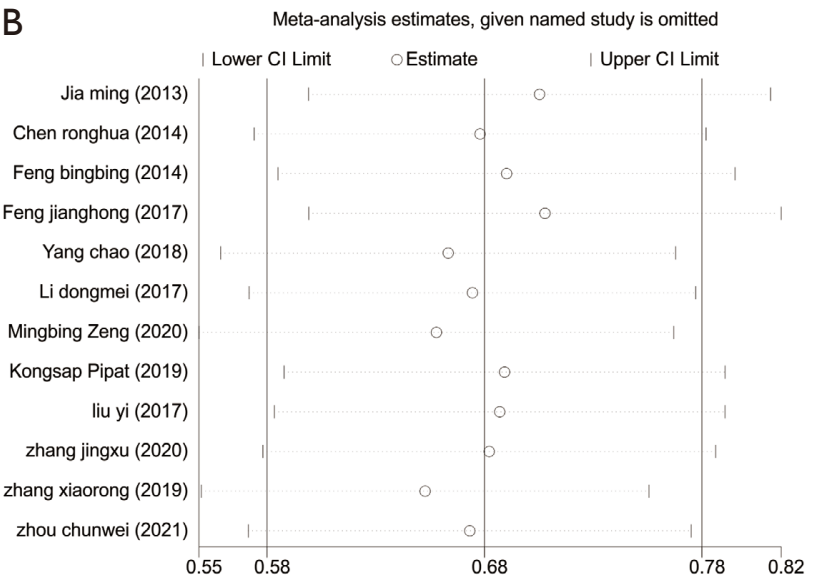

C
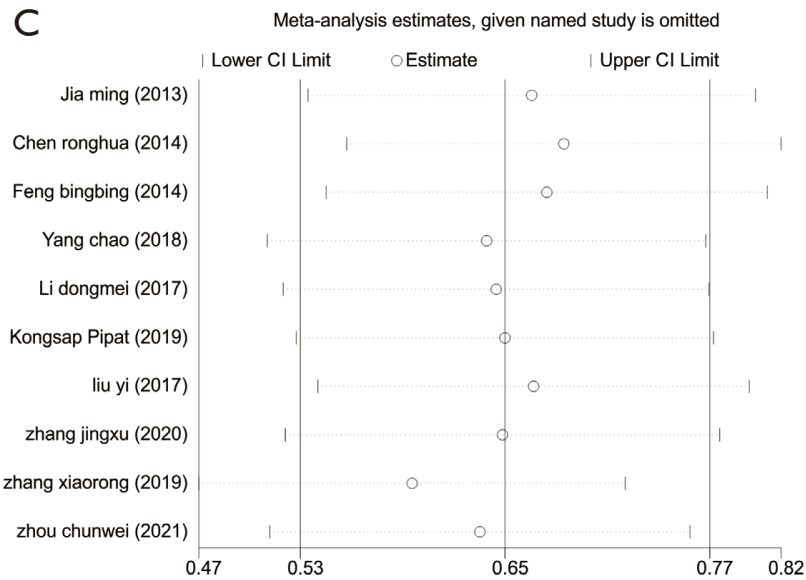

Figure 7 Sensitivity analysis of the 2 groups. (A) Corneal endothelial cell count before surgery, (B) 1 month after surgery, (C) 3 months after surgery. 
with capsular rupture (6). Therefore, researchers have established a modified phacoemulsification, but this method is still in the experimental stage and has not been recognized. In this study, 12 articles that met the inclusion criteria were collected; we found that the modified phacoemulsification had better therapeutic effect and reduced the incidence rate of postoperative complications. In a study by Tang et al., compared with conventional surgery, the modified phacoemulsification (with lower ultrasound energy) and intraocular lens implantation was shown to better improve visual acuity and effectively reduce corneal edema and anterior chamber inflammation (25). Collectively, the modified phacoemulsification is safer and more effective.

A cataract is defined as an opacification of the lens, which can be divided into 2 types: secondary or secondary disease (such as diabetes), and primary eye diseases (uveitis, acute angle-closure) (26). Over time, cataracts cause blurred vision, halos and glare, and ultimately blindness. Traditional phacoemulsification is the most common cataract surgery in the world, which can break the lens into small fragments by ultrasound and then suck them out from the anterior chamber through the phacoemulsification tip (27). However, cataract surgery, like any other surgical method, carries the risk of infection and bleeding, which easily causes endophthalmitis and posterior capsule opacification (28). By contrast, modified phacoemulsification has shown good advantages here. In a clinical trial of 31 patients with cataract after vitrectomy, Yu et al. found that the modified phacoemulsification technique combined with anterior chamber phacoemulsification is a safe and effective treatment for cataract after vitrectomy; this method improved ocular inflammation, intraocular pressure and other conditions, and achieved best-corrected visual acuity (BCVA) (29). Chen $e t$ al. evaluated phacoemulsification combined with internal tamponade as a safe and minimally invasive method for cyclodialysis cleft repair and cataract treatment (30). The results of this meta-analysis showed that the modified phacoemulsification could effectively improve the corneal endothelial cell count of patients at different stages, reduce postoperative complications, and improve visual acuity. Collectively, this surgical method is safe and effective, and is worthy of clinical application.

\section{Conclusions}

In summary, this meta-analysis highlighted that compared with traditional phacoemulsification, the modified phacoemulsification is safer and more effective in the treatment of high myopia with cataract. However, due to the limitation of the number and quality of included studies, the above conclusions still need to be verified via more high-quality studies.

\section{Acknowledgments}

Funding: Quality of Life Care Research Project of China Life Care Association (HL20210104); Humanities and Social Sciences Research Project of Hubei Provincial Department of Education (18D070); Research Project of Taihe Hospital, Shiyan (2020JJXM022; 2019JJXM004).

\section{Footnote}

Reporting Checklist: The authors have completed the PRISMA reporting checklist. Available at https://dx.doi. org/10.21037/apm-21-2215

Conflicts of Interest: All authors have completed the ICMJE uniform disclosure form (available at https://dx.doi. org/10.21037/apm-21-2215). The authors have no conflicts of interest to declare.

Ethical Statement: The authors are accountable for all aspects of the work in ensuring that questions related to the accuracy or integrity of any part of the work are appropriately investigated and resolved.

Open Access Statement: This is an Open Access article distributed in accordance with the Creative Commons Attribution-NonCommercial-NoDerivs 4.0 International License (CC BY-NC-ND 4.0), which permits the noncommercial replication and distribution of the article with the strict proviso that no changes or edits are made and the original work is properly cited (including links to both the formal publication through the relevant DOI and the license). See: https://creativecommons.org/licenses/by-nc-nd/4.0/.

\section{References}

1. McCarty CA, Livingston PM, Taylor HR. Prevalence of myopia in adults: implications for refractive surgeons. J Refract Surg 1997;13:229-34.

2. Leo SW, Young TL. An evidence-based update on myopia and interventions to retard its progression. J AAPOS 
2011;15:181-9.

3. Ikuno Y. OVERVIEW OF THE COMPLICATIONS OF HIGH MYOPIA. Retina 2017;37:2347-51.

4. Pan CW, Boey PY, Cheng CY, et al. Myopia, axial length, and age-related cataract: the Singapore Malay eye study. Invest Ophthalmol Vis Sci 2013;54:4498-502.

5. Kanthan GL, Mitchell P, Rochtchina E, et al. Myopia and the long-term incidence of cataract and cataract surgery: the Blue Mountains Eye Study. Clin Exp Ophthalmol 2014;42:347-53

6. Cetinkaya S, Acir NO, Cetinkaya YF, et al. Phacoemulsification in eyes with cataract and high myopia. Arq Bras Oftalmol 2015;78:286-9.

7. Szijártó Z, Schvöller M, Pótó L, et al. Pseudophakic retinal detachment after phacoemulsification. Ann Ophthalmol (Skokie) 2007;39:134-9.

8. Poulsen CD, Peto T, Grauslund J, et al. Epidemiologic characteristics of retinal detachment surgery at a specialized unit in Denmark. Acta Ophthalmol 2016;94:548-55

9. Wang S, Wang H, Ophthalmology DO. Efficacy and safety of laser iridoplasty and ultrasonic phacoemulsification combined with intraocular lens implantation in the treatment of acute angle closure glaucoma. Chinese Journal of Ophthalmologic Medicine 2015;10:309-15.

10. Tosi GM, Casprini F, Malandrini A, et al. Phacoemulsification without intraocular lens implantation in patients with high myopia: long-term results. J Cataract Refract Surg 2003;29:1127-31.

11. Zheng HF, Wang XF, Zhang JW, et al. Clinical analysis of modified phacoemulsification in 28 cases of high myopia with cataract. Chinese Journal of Ocular Trauma and Occupational Eye Disease 2018;237:102.

12. Zhang XR, Guo JB. Clinical Analysis of Modified Phacoemulsification for High Myopia with Cataract. Systems Medicine 2019;56:103-8.

13. Zhang QW. Clinical efficacy of modified phacoemulsification in the treatment of high myopia with cataract. China Practical Medical 2017;12:83.

14. Liu Y, Chen SY, Zhang XG, et al. Clinical Analysis of Modified Phacoemulsification for Cataract Complicated with High Myopia. China \& Foreign Medical Treatment 2017;29:051.

15. Kongsap P. Central corneal thickness changes following manual small incision cataract surgery versus phacoemulsification for white cataract. Rom J Ophthalmol 2019;63:61-7.

16. Zeng M, Wang R, Cheng B, et al. Effectiveness of intraoperative intraocular lens use on improving surgical safety for dense cataract phacoemulsification: a randomized controlled trial. Sci Rep 2020;10:1600.

17. Dong-Mei LI, Ophthalmology DO, Hospital RP. Clinical Analysis of Modified Phacoemulsification in Treatment of High Myopia and Cataract. China \& Foreign Medical Treatment 2017;5:176.

18. Yang C, Zhang SQ. Effect and complications of modified phacoemulsification in the treatment of high myopia with cataract. Clinical Research and Practice 2018;3:86-7.

19. Feng JH. Clinical analysis of 79 cases of high myopia with cataract treated by modified phacoemulsification. The Medical Forum 2017;21:4958-9.

20. Feng B, Zhang J, Ophthalmology DO. Clinical analysis of 150 cases of cataract with high myopia phacoemulsification operation of the application of the modified. China Medicine and Pharmacy, 2014.

21. Jia M. Clinical analysis of modified phacoemulsification in 80 cases of high myopia with cataract. Contemporary Medicine 2013;000:70-71.

22. Zhou C. Clinical study of modified phacoemulsification in the treatment of high myopia with cataract. World's latest medical information Abstracts 2021;21:96-7.

23. Neuhann IM, Neuhann TF, Heimann H, et al. Retinal detachment after phacoemulsification in high myopia: analysis of 2356 cases. J Cataract Refract Surg 2008;34:1644-57.

24. Kuhn F, Aylward B. Rhegmatogenous retinal detachment: a reappraisal of its pathophysiology and treatment. Ophthalmic Res 2014;51:15-31.

25. Tang Y, Tan J, Zhou X, et al. Modified phacoemulsification plus goniosynechialysis compared with conventional surgery for cataract and glaucoma. Exp Ther Med 2020;19:131-6.

26. Lee CM, Afshari NA. The global state of cataract blindness. Curr Opin Ophthalmol 2017;28:98-103.

27. Boulter T, Bernhisel A, Mamalis C, et al. Phacoemulsification in review: Optimization of cataract removal in an in vitro setting. Surv Ophthalmol 2019;64:868-75.

28. Durand ML. Bacterial and Fungal Endophthalmitis. Clin Microbiol Rev 2017;30:597-613.

29. Yu T, Han XG, Li YM, et al. Phacoemulsification in the anterior chamber: An alternative surgical technique in post-vitrectomy cataract. Pak J Med Sci 2018;34:1512-6.

30. Chen J, Jing Q, Gao W, et al. Cyclodialysis cleft repair and 
cataract management by phacoemulsification combined with internal tamponade using modified capsular tension ring insertion. Graefes Arch Clin Exp Ophthalmol

Cite this article as: Qi J, Yuan J, Zhou Y, Guo R, Zhang Y, Dai Q, Liu Y. Clinical efficacy of modified phacoemulsification in the treatment of high myopia with cataract: a systematic review and meta-analysis. Ann Palliat Med 2021;10(10):10556-10566. doi: 10.21037/apm-21-2215
2018;256:2369-76.

(English Language Editor: J. Jones) 